\title{
Study of Common Requested Radiographs and Relative Exposure Dose in Qassim State
}

\author{
Abdulrahman Abdullah Saad Alsayyari ${ }^{1}$, Mohammed Ahmed Ali Omer ${ }^{1,2, *}$, \\ Nasraldeen Alnaeem Mohammed Alkhidir ${ }^{1}$, Abdelmoneim Saeed Ahmed Auod ${ }^{1}$ \\ ${ }^{1}$ College of Applied Medical Science-Department of Radiologic Technology- Qassim University, Buraidah, KSA \\ ${ }^{2}$ Department of Radiotherapy \& Nuclear Medicine, College of Medical Radiologic Science, Sudan University of Science and Technology, \\ Khartoum, Sudan
}

\section{Email address:}

a.alsayyari@qu.edu.sa (A. A. S. Alsayyari), alkajam@gmail.com (M. A. A. Omer), nasro999@gmail.com (N. A. M. Alkhidir), moneim.saeed8@gmail.com (A. S. A. Auod)

${ }^{*}$ Corresponding author

\section{To cite this article:}

Abdulrahman Abdullah Saad Alsayyari, Mohammed Ahmed Ali Ome, Nasraldeen Alnaeem Mohammed Alkhidir, Abdelmoneim Saeed Ahmed Auod. Study of Common Requested Radiographs and Relative Exposure Dose in Qassim State. International Journal of Medical Imaging. Vol. 5, No. 2, 2017, pp. 14-18. doi: 10.11648/j.ijmi.20170502.12

Received: February 20, 2017; Accepted: March 1, 2017; Published: March 18, 2017

\begin{abstract}
The objective of the article was to study the common requested radiographs and relative exposure dose in Qassim state in Kingdom of Saudi Arabia. The method was retrospective and analytical study for collected variables as radiographs, relative entrance surface dose (ESD) and the effective dose, patient age, gender and causative factors. The analysis with excel software revealed that: the common requested radiographs were skull, abdomen and chest with male incidence as $75 \%, 72.2 \%$ and $64 \%$ respectively relative to whole sample. Traffic accident $(71 \%)$ and fall-down (45\%) were the most causative factors among male and female respectively, with injuries as skull fissure fracture (77\%) and intracranial hemorrhage (23\%). The skull radiographs noted among the age group of 11-21 years and peaking at 36\% among the age group of 22-32 years. The requested abdominal radiographs appeared among the age group of $13-21$ years; with frequency of (19\%) and peaking at $30 \%$ among the age group of 22-30 years; with injuries as spleen ruptures (42\%) and liver (27\%). The chest radiographs observed among age group of 3-13 years; with frequency of 4\% and peaking among age groups of 14-24 \& 25-35 years old with frequencies of $19 \%$ and $21 \%$ respectively, and injuries as Ribs fracture (55\%), ribs dislocation (15\%), pierced lung (20\%) hemorrhage (10\%). The average ESD for abdomen, skull and the chest radiographs were $1.93 \pm 0.8,1.53 \pm 0.6$ and $0.21 \pm 0.2 \mathrm{mGy}$ which were increase linearly following the aging. And the average effective doses were $0.24 \pm 0.1,0.1 \pm 0.1$ and $0.4 \pm 0.2 \mathrm{mSv}$ respectively.
\end{abstract}

Keywords: Skull, Abdomen, Chest, Exposure, Radiation

\section{Introduction}

The medical requested examinations (radiologic or laboratory) are common for routine medical checkup, follow up and in case of emergencies; however the rate and the incidence of such examinations influenced by some factors; as the number population, wealth of population, age factor, gender, habits, etc. And the common diagnostic modalities used in radiology field are ultrasound which is a friendly applicable, available and safe in diagnosis for soft tissue pathologies in addition to $\mathrm{x}$-ray and magnetic resonance imaging (MRI). However Kristin and Bjorn, [1] highlighted some additional factors that may influence the rate of requested radiograph out of questionnaire article which were: (a) new radiological technology, (b) peoples' demands, (c) clinicians' intolerance for uncertainty, (d) expanded clinical indications and (e) availability in addition to over investigation and insufficient referral information were reported as the most frequent causes of unnecessary investigations. And due to such factors the general request or the frequency of radiography has been roughly doubled and in some countries tripled during the five years preceded 2008 as has been reported by the United Nations Scientific Committee on the Effects of Atomic Radiation (UNSCEAR) [2]. 
The use of radiological investigations have been accepted and justified for medical practice in terms of clear clinical benefits to the patient, and small radiation risks. And what is so encourage-able for utilizing $x$-ray in imaging is the fact stated by ARPANSA [3] that "patient would need to have approximately 38 chest $x$-rays to receive an amount of radiation similar to that of normal background radiation that everyone receives for one year from the environment". However, even small radiation doses are not entirely without risk, and moreover certain committed mistakes may increase the exposure dose to patient and staff which in turn would increase the stochastic effects; hence some studies $[4,5]$ impose a responsibility on imaging departments to ensure that all exposures to ionizing radiation should be justified, and that doses are optimized and consequently the organizations and individuals using ionizing radiation must comply with these regulations.

The compliance of organizations and individuals dealing with ionizing radiation will results in avoiding the major health risks (Cancer occurring many years after the radiation exposure and Health problems in the children due to damage to the reproductive cells in the body) that occur as a result of exposure to medical ionizing radiation which is agreed with unanimous consensus which stated that: the decreasing of exposure dose would decreases the stochastic effects linearly without threshold [6, 7]. The patient dose in the field of radiography has been quantified in term of Entrance Surface Dose (ESD)/radiograph or in term of Dose Area Product (DAP) for entire examination [8] and for radiation risk better in term of effective dose. The major benefit of using the effective dose is that: it accounts for the absorbed doses and relative radio-sensitivities of the irradiated organs in the patients and, therefore better quantifies the patient risk [9]. However the estimated dose for radiographic case depends on several parameters, such as patient's age and weight, body region and clinical indication. These data are normally stored in several formats and with different nomenclatures, which hinder the continuous and automatic monitoring of these indicators and the comparison between several institutions and equipment unless studied and sorted out in term of ESD/radiograph or DAP, dose length product (DLP). The frequent incidences of radiographic examination requests have significant impact in economic status of the countries, quality of medical services and patient and staff risks [1012], as these common request of radiologic investigations have consequences of increasing radiation doses; that turn the attention of many scholars $[13,14]$ as well as the trend of this study in addition to directing the authorized parts in Qassim state to layout some proposed solving for the common and high incidence factors (Traffic accident, violence driving and fall-down) that increase the request of radiographic investigation.

\section{Methodology}

This is a retrospective study based on extraction of common requested radiographs that performed for the patients during January 1- July 1, 2016 in different hospitals' and clinics' picture archiving communication systems (PACS) at Qassim state, after the approval of the local ethical committee of the institutions for the study method and signing the informal consent. The x-ray systems were digital radiography (GE, healthcare, model Al01CII, 2011-German), applied kVp 75 2 , mAs $20 \pm 3$ for the skull, $\mathrm{kVp} 65 \pm 5, \mathrm{mAs} 23 \pm 3$ for abdomen and $\mathrm{kVp} 70 \pm 2$, mAs $20 \pm 3$ for chest while the focal film distance was 100 $\mathrm{cm}$ for all cases. The total common cases encountered have been under focus by the researchers and the relative exposure doses, which were represented the skull; chest $\mathrm{x}$ ray and abdomen with relative number as 70,83 , and 88 patients respectively. The collected and sorted data were gender, age, causative factors, abdomen radiographs, chest radiographs, and skull radiographs with their relative entrance surface doses (ESD) in mGy and effective dose (EffD) in $\mathrm{mSv}$. The doses have been derived from the product of system output, mAs, back scatter factor BSF (1.4), focal detector distance FDD and focus - skindistance FSD based on the equations $(1,2)$ stated by ICRU, [15] and Davies et al, [16]:

$$
\text { Dose }(\mathrm{mGy})=\frac{\text { output }(m G y / m A s) \times(m A s) \times(B S F) \times(F D D)^{2}}{(F S D)^{2}}
$$

Then the effective dose in $\mathrm{mSv}$ has been derived from the equation stated by International Commission on Radiological Protection [16].

$$
E f f D=\sum \frac{W_{T}\left[H_{T}(\text { female })+H_{T}(\text { male })\right]}{2}
$$

Where $\mathrm{W}_{\mathrm{T}}$ refers to weighting factor for organ or tissue and $\mathrm{H}_{\mathrm{T}}$ refers to equivalent dose to organ or tissue.

\section{Result}

The following results will highlighting the common requested radiographs, the relative exposure doses, gender and age and causative factors, being plotted in forms of bars, correlation and graphs in Qassim state.

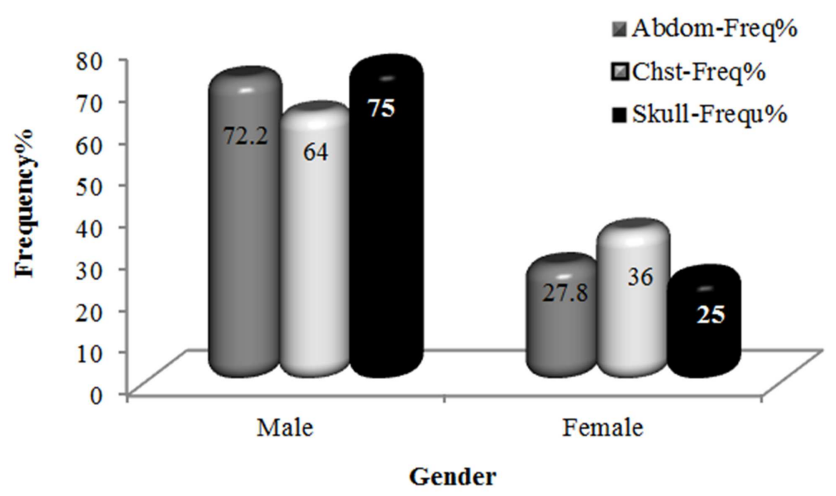

Figure 1. Shows the distribution of requested radiographic cases based on gender. 


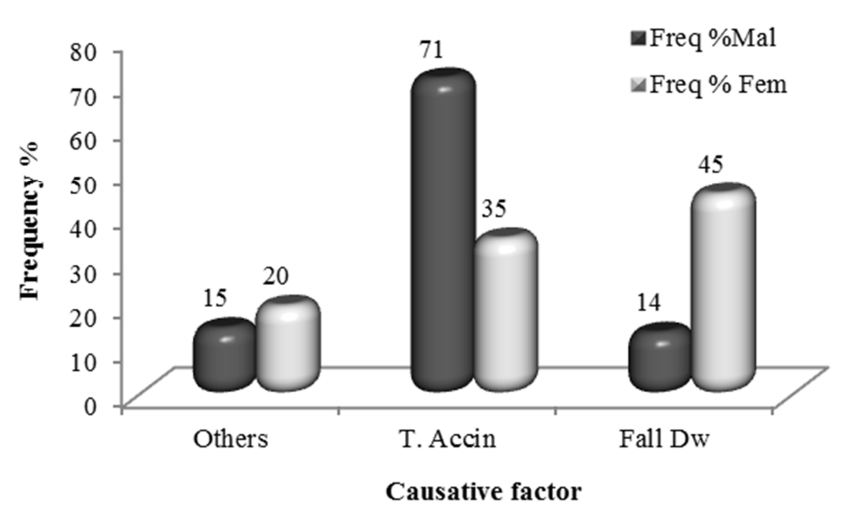

Figure 2. Shows the distribution of requested radiographic cases based on causes.

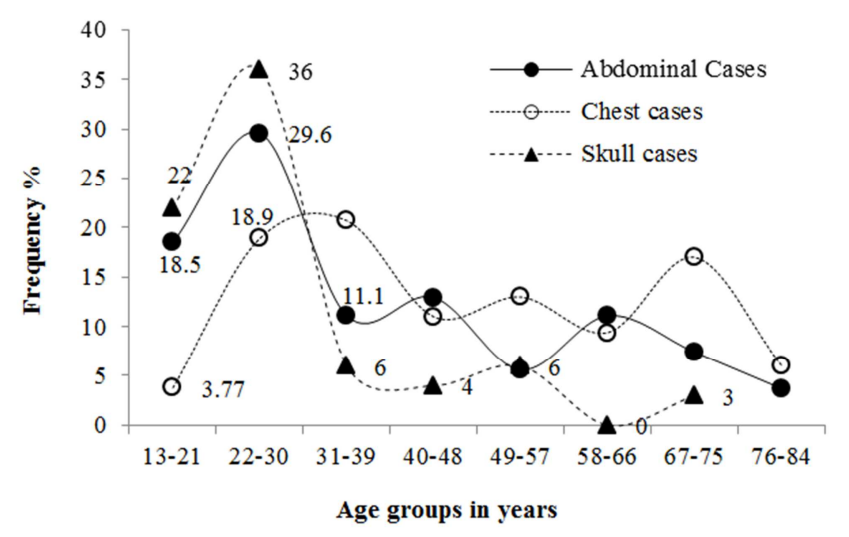

Figure 3. Shows the distribution of the common requested radiographic cases based on age.

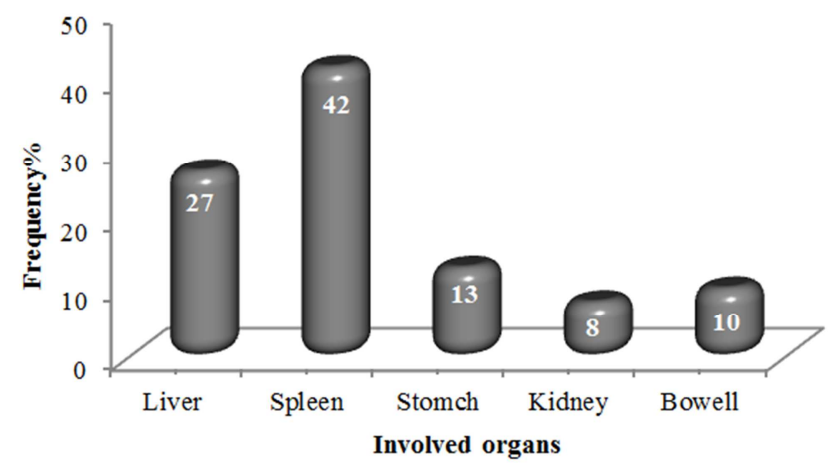

Figure 4. Shows the frequency of abdominal injured organs in traumatic accident.

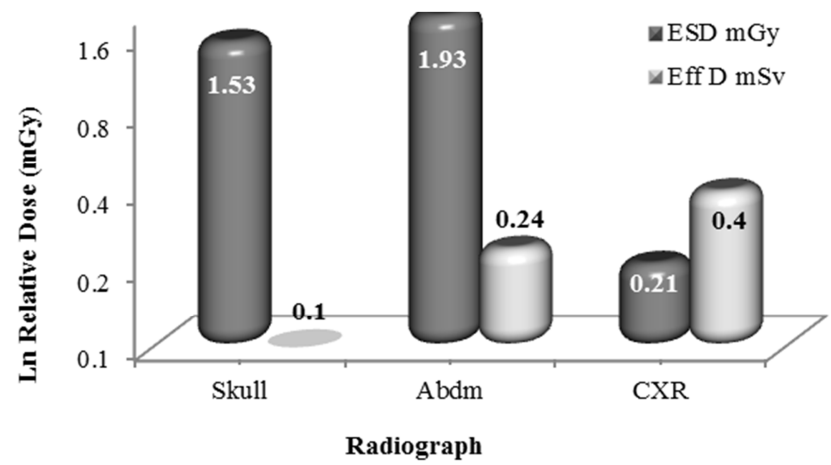

Figure 5. Shows the average ESD in $m G y$ \& EffD in $m S v$ received by common anatomical site radiography.

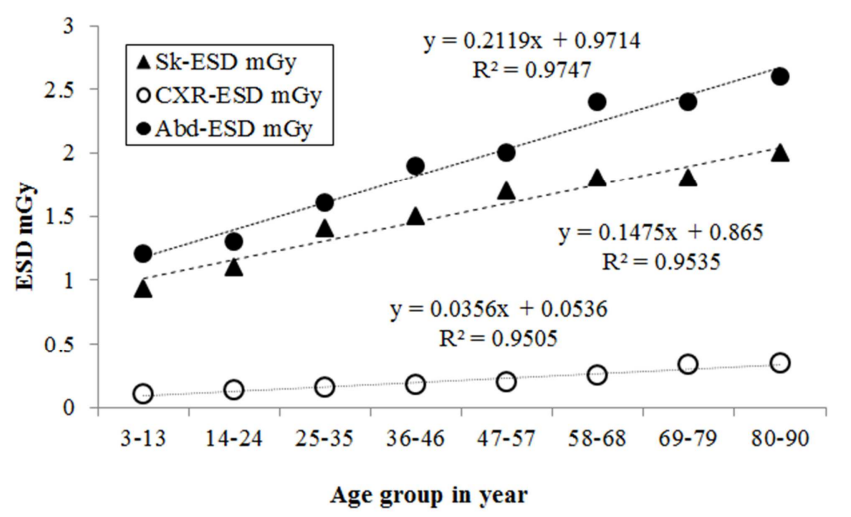

Figure 6. Shows the correlation between entrance surface dose in mGy and patient age group in radiography.

\section{Discussion \& Analysis}

Figure 1: shows the distribution of requested radiographic cases based on gender. It revealed that: the common requested radiographic cases were the skull, abdomen and chest with incidences among male representing 75\%, 72.2\% and $64 \%$ respectively relative to total sample. However such high requested radiographs for male were attributed to traffic accident factor with $71 \%$ relative to other causative factors such as fall down which represents the common factor for requested radiographic exams among female $45 \%$ (Figure 2), while traffic accident represents only $35 \%$ among female. In comparison with this study, Colin et al, [18] stated that: the road traffic accident has been as a large burden among developing countries which accounting for $85 \%$ of annual deaths and $90 \%$ of the disabilities and as well the majority of victims were male with $73 \%$ relative to female and the common involved age group was $15-29$ and 30-44 years old. In deed such high incidence of traffic accident became in needful to urgent examinations which in turn will increase the radiographic exams requests and other modalities of investigation that burden the economic status in families and countries.

Figure 3: shows the distribution of requested radiographic cases based on age, in which the request skull radiographs have been noted among the age group of 11-21 years old and peaking at $36 \%$ among the age group of $22-32$ years old then the request of exams decreased rapidly (5\% in average) following aging; the most common injuries were fissure skull fracture $(77 \%)$ and intracranial hemorrhage $(23 \%)$, while second common requested radiographs were the abdominal cases which noted among the age group of 13-21 years old with frequency of (19\%) and peaking at 30\% among the age group of 22-30 years old as agreed with Mousami et al, [19], then the request of exams decreased rapidly $(8.6 \%$ in average) following aging; and the most common noted injuries were spleen ruptures $(42 \%)$ and liver (27\%) (Figure 4) as agreed with Innocent and Mbale, [20] which have been confirmed in ultrasound sections. And the third common requested cases were the chest radiographs which have been noted among age group of 3-13 years old with frequency of $4 \%$ and peaking among age groups of $14-24 \& 25-35$ years 
old with frequency of $19 \%$ and $21 \%$ respectively then the request frequency decreases following aging to an average of $11 \%$, with common injuries as Ribs fracture $(55 \%)$, ribs dislocation (15\%), Pierced lung (20\%) hemorrhage (10\%). Such high requested radiographs among early youth and teenage ascribed to common violence driving, high speed and as well the customary teenage drivers among the natives of Qassim state. These common requested cases (abdomen, skull and the chest radiographs), inevitably accompanied with considerable radiation exposure dose in view of entrance surface dose (ESD) in Milli-Gray ( $\mathrm{mGy}$ ) and effective dose (EffD), in Milli-Severt $(\mathrm{mSv})$ which were $1.93 \pm 0.8,1.53 \pm 0.6$ and $0.21 \pm 0.2 \mathrm{mGy}$ for ESD respectively and the effective doses for requested chest, abdomen and skull radiographs were $0.4 \pm 0.2,0.24 \pm 0.1$ and $0.1 \pm 0.1 \mathrm{mSv}$ respectively as shown in Figure (5). In comparison with the study done by Akbar et al, [21] in which the mean ESD were 2.01, 1.39 and $0.37 \mathrm{mGy}$ and the ED were 0.28/abdomen, $0.01 /$ skull and $0.04 /$ chest $\mathrm{mSv}$; it is so obvious that the current study showed less exposure of ESD for abdomen by 0.08 , greater dose by $0.14 \mathrm{mG}$ for skull and less exposure dose by $0.16 \mathrm{mGy}$ for chest radiographs. And as well the ED showed that the current study revealed greater exposure dose by $3.6 \mathrm{mSv}$ for chest radiography, less exposure dose by 0.04 $\mathrm{mSv}$ for abdomen and greater exposure dose by $0.09 \mathrm{mSv}$ for the skull, however all exposure doses are still within the limits stated by authorized organizations. Also for chest exams; the current study showed less ESD compared with study done by Kofi et al, [22] which was $0.27 \mathrm{mGy}$ while the ED so higher than they obtained $(0.02 \mathrm{mSv})$.

The variation of exposure dose have been noted by many scholars [23-26] even among same aged patients and size, which indicates the influence of other parameters affecting the general exposure dose. However the data also revealed that: the ESD for the requested cases (abdomen, skull and the chest radiographs) have been increased following the aging in a linear significant correlation $\left(\mathrm{R}^{2}=0.9\right)$ that could be fitted to equation of the form: $y=0.2119 x+0.9714, y=0.1475 x+0.865$ and $y=0.0356 x+$ 0.0536 respectively; where $x$ refers to the age in years and $y$ refers to ESD in mGy as shown in Figure (6). Indeed the increment of ESD for abdominal cases ascribed to usage of wide large radiation field which is in proportional with aging and due to tissue quality factor in case of effective dose. In comparison with the exposure level stated by International Atomic Energy Agency, these obtained results are still within or below the limits $[27,28]$.

\section{Conclusion}

Qassim state in Kingdom of Saudi Arabia, like other universe cities, having the common requested radiographs as skull, abdomen and chest which were ascribed to traffic accidents and violence driving among male aged 14-24 \& 2535 years old and the falling down was the causes for female and the notable cases were the teenage victims due to violence driving. However the exposure doses were below or within the permissible range.

\section{References}

[1] Kristin B Lysdah and Bjørn M Hofmann. (2009). What causes increasing and unnecessary use of radiological investigations? A survey of radiologists' perceptions. BMC Health Services Research, 9:155. doi: 10.1186/1472-6963-9-155.

[2] United Nations Scientific Committee on the Effects of Atomic Radiation. (2000). Sources and effects of ionizing radiation: report to the General Assembly, annex D, medical radiation exposures. New York, NY: United Nations.

[3] Australian Radiation Protection \& Nuclear Safety Agency (ARPANSA) (2008) Code of practice: Radiation Protection in the Medical Applications of Ionizing Radiation (Radiation Protection Series Publication No. 14) ISBN 978-0-9803236-34, ISSN 1445-9760-Australia.

[4] Malone J., Fipem, R. Guleria, C. Craven, P. Horton, H. J. A. Rvinen, J. Mayo, G. O. Reilly, E. Picano, D. Remedios, Frcr, J. Le Heron, Facpsem, M. Rehani, O Holmberg, and R Czarwinski. (2012). Justification of diagnostic medical exposures: some practical issues. Report of an International Atomic Energy Agency Consultation. The British Journal of Radiology, 85, 523-538.

[5] Maria Murray (2012) Ionizing Radiation on Medical Exposure IR(ME)R 2000 and IR(ME) Amendment Regulations 2006 \& 2011. ISBN: 9781-871101-87-5-UK.

[6] Einstein AJ, Henzlova MJ, Rajagopalan S. (2007). Estimating Risk of Cancer Associated with Radiation Exposure From 64Slice Computed Tomography Coronary Angiography. JAMA, 298 (3):317-323.

[7] Mettler F, Huda W, Yoshizumi T, Mahesh M. (2008). Effective Doses in Radiology and Diagnostic Nuclear Medicine: A Catalog. Radiology, 248(1):254-263.

[8] European Commission (1996) European guidelines on quality criteria for diagnostic radiographic images. Publication EUR 16260 EN. Brussels, Belgium: European Commission.

[9] ICRP. (1991). Recommendations of the ICRP publication 60, Annals of ICRP, Pergamon Press, Oxford.

[10] Fisher ES, Welch HG. (1999). Avoiding the unintended consequences of growth in medical care: how might more be worse? JAMA, 281:446-453.

[11] Otero HJ, Ondategui-Parra S, Nathanson EM, Erturk SM, Ros PR: (2006). Utilization management in radiology: basic concepts and applications. J Am Coll Radiol, 3:351-357.

[12] Iglehart JK: (2006). The new era of medical imaging-progress and pitfalls. N Engl J Med, 354:2822-2828.

[13] EU Council: (1997). Health protection of individuals against the dangers of ionizing radiation in relation to medical exposure. EU Directive 97/43/EURATOM of 30 June 1997.

[14] NCRP: Report No. 160. (2009). Ionizing Radiation Exposure of the Population of the United States Bethesda: National Council on Radiation Protection \& Measurements; 2009.

[15] International Commission for Radiation Units and Measurements. (2005). Patient dosimetry for X-rays used in medical imaging. J. ICRU, 5, 4-6. 
[16] Davies, M., McCallum, H., White, G., Brown, J., \& Helem, M. (1997). Patient dose audit in diagnostic radiography using custom designed software. Radiography, 3, 17-25. Diretrizes de Protecaeo Radiol_o gica.

[17] International Commission on Radiological Protection-103. (2007). Recommendations of the international commission on radiological protection. Annals of ICRP. Oxford, UK: Pergamon Press.

[18] Colin D. Mathers, Christina Bernard, Kim Moesgaard Iburg, Mie Inoue, Doris Ma Fat, Kenji Shibuya, Claudia Stein, Niels Tomijima, Hongyi Xu. (2003). Global Burden of Disease in 2002: data sources, methods and results: WHO-Global Programme on Evidence for Health Policy Discussion Paper No. 54.

[19] Mousami Singh, Amit Kumar, Anoop Kumar Verma, Sanjeet Kumar, Abhas Kumar Singh. (2012). Abdominal Organ Involvement in Blunt Injuries. J. Indian Acad Forensic Med. ISSN 0971-0973, vol. 34 (1), P: 24-26.

[20] Innocent Gerald Makoba, Mbale Hospital. (2001). Splenic injury following trauma: The role of ultrasonography. African Health Sci. 1(1):22-26.

[21] Akbar Aliasgharzadeh, Ehsan Mihandoost, Mahboubeh Masoumbeigi, Morteza Salimian \& Mehran Mohseni. (2015). Measurement of Entrance Skin Dose and Calculation of Effective Dose for Common Diagnostic X-Ray Examinations in Kashan, Iran. Global Journal of Health Science; 7(5), 202207.

[22] Kofi Ofori, Samuel W. Gordon, Emmanuel Akrobortu, Adriana A. Ampene, Emmanuel O. Darko. (2014). Estimation of adult patient doses for selected X-ray diagnostic examinations. Journal of Radiation Research and Applied Sciences, 7, 459-462.

[23] Zenone, F., Aimonetto, S., Catuzzo, P., Peruzzo Cornetto, A., Marchisio, P., Natrella, M., Tofani, S. (2012). Effective dose delivered by conventional radiology to Aosta Valley population between 2002 and 2009. Br J. Radiol, 85(1015), e330-338. http://dx.doi.org/10.1259/bjr/19099861.

[24] Osei, E. K., \& Darko, J. (2013). A survey of organ equivalent and effective doses from diagnostic radiology procedures. ISRN Radiol, 2013, 204346. http://dx.doi.org/10.5402/2013/204346.

[25] Shahbazi-Gahrouei, D., \& Baradaran-Ghahfarokhi, M. (2013). Assessment of entrance surface dose and health risk from common radiology examinations in Iran. Radiat Prot Dosimetry, 154(3), 308-313. http://dx.doi.org/10.1093/rpd/ncs244.

[26] Shirin Shandiz, M., Bahreyni Toosi, M. T., Farsi, S., \& Yaghobi, K. (2014). Local reference dose evaluation in conventional radiography examinations in Iran. $J$ Appl Clin Med Phys, 15(2), 4550. http://dx.doi.org/10.1120/jacmp.v15i2.4550.

[27] IAEA. (2012). Radiation protection in pediatric radiology Safety reports series No. 71. Vienna - Austria.

[28] International Atomic Energy Agency and the Commission of the European Communities (1991-1993). (1995). Radiation doses in diagnostic radiology and methods for dose reduction. Vienna - Austria. 